\title{
OPTIONS FOR REDUCING OXIDATIVE TOXICITY OF L-DOPA BY COMBINATION WITH SYNTHETIC OR NATURAL RADICAL PROTECTORS
}

\author{
G. Nikolova* \\ Department of Chemistry and Biochemistry, Medical Faculty, Trakia University, \\ Stara Zagora, Bulgaria
}

\begin{abstract}
Parkinson disease (PD) is a multifactorial disease that is not well-established. It takes a leading place among contemporary frequent diseases of the central nervous system (CNS). The levodopa (L-dopa) clinical effect is diminished by motor complications resulting from prolonged treatment. Due to the Ldopa neurotoxic effect in the disease treatment, the L-dopa administration is delayed as long as possible in order to avoid side effects. In addition, combining L-dopa therapy with antioxidants (from natural or synthetic origin), may decrease side-effects and provide symptomatic relief. The aim of the current research is through experimental model of healthy mice to explore the possibility to reduce the oxidative stress (OS) induced by the L-dopa drug after its combining with: an essential oil isolated from Rosa damascena Mill., the vitamin C and synthetic antioxidant 1-ethyl-3- [4- (2,2,6,6tetramethylpiperidine-1-oxyl)] - 1-nitrosourea SLENU. The antioxidants protective effects against the L-dopa oxidative toxicity were evaluated through the oxidative stress indicators - the lipid and protein oxidation end products - measured as MDA, protein carbonyl content, and advanced glycation end products (AGEs) in blood plasma of experimental mice.
\end{abstract}

Key words: Parkinson disease, L-dopa, natural antioxidants, synthetic antioxidants, PCC, AGEs

\section{ITRODUCTION}

Parkinson disease (PD) is a multifactorial disease that is not well-established. It takes a leading place among contemporary frequent diseases of the central nervous system (CNS) [1]. The major clinical disturbances in PD are dopamine depletion consequence in the neostriatum, due to dopaminergic neurons' degeneration [2]. The agent that initiates the disease is unknown. The drug therapy depends on disease severity, remains relatively nonspecific and limited long term efficacy. In the early disease stages, is used a monoamine oxidase $\beta$-inhibitor. Initially, the drug is used to inhibit the dopamine degradation. In later disease phases, the patients are treated with Levodopa (L-dopa) a dopamine precursor [3]. The dihydroxyphenylalanine (Levodopa, Ldopa) - is a "gold standard" and the most effective symptomatic treatment for PD, against which new drugs are compared [4]. A number of therapies have been developed in an

*Correspondence to: Galina Nikolova, Department of chemistry and biochemistry, Medical Faculty, Trakia University, 11 Armeiska Str., 6000 Stara Zagora,Bulgaria, gallina_nikollova@abv.bg attempt to improve the disease treatment, such as dopaminergic agonists and inhibitors COMT and MAO-B, but most patients still depend on L-dopa because it is the most able to control the PD symptoms [5]. The L-dopa clinical effect is diminished by motor complications resulting from prolonged treatment. Due to the L-dopa neurotoxic effect in the disease treatment, the L-dopa administration is delayed as long as possible in order to avoid side effects. In addition, combining L-dopa therapy with antioxidants (from natural or synthetic origin), may decrease side-effects and provide symptomatic relief.

Natural antioxidants are isolated from different parts of plants, like flowers, seeds, leaves, roots, bark and their phenolic extracts can slow the lipid oxidation [6]. Rose oil from Rosa damascena mill has a wide range of medicinal properties. It contains various substances with antioxidant activity as anthocyanins, flavonoids, terpenes and glycosides [7, 8], kaempferol and quercetin [9]. Moreover, essential rose oil has useful medical properties such as antifungal and antiviral effects, 
improves memory, tones up, and depressions relieves [10].

The vitamin $\mathrm{C}$ possesses strong antioxidant properties, and interacts with hydrogen peroxide $\left(\mathrm{H}_{2} \mathrm{O}_{2}\right)$, hydroxyl $(\cdot \mathrm{OH})$ and superoxide $\left(\cdot \mathrm{O}_{2}{ }^{-}\right)$radicals, and turning them into non-radical products, providing cells with a free radical "neutralizer" [12]. Moreover, the Vitamin C exhibit pro- oxidant properties in the presence of free transition metals, because it reduces ferrions to ferro-ions in a Fentonlike reaction and in the $\mathrm{H}_{2} \mathrm{O}_{2}$ presence stimulate the hydroxyl radicals formation [13]. Whether the ultimate effect will be a prooxidant or an antioxidant depends on the ratio of the ascorbic acid concentration to the available ferrions [14]. At sufficiently high concentrations, ascorbic acid reduces and destroys the formed radicals [15]. Plasma antioxidants traceability under oxidative stress indicates that the ascorbic acid level has been lowered at the earliest, and after depletion, lipid peroxidation has developed, even if plasma tocopherol is in normal concentrations [15].

Over the last decade, many researchers have focused their attention on creating and researching new, more effective synthetic antioxidants to inhibit free-radical reactions mediating specific lesions in biomolecules [16]. The new class discovery of paramagnetic compounds from the sterically hindered $\mathrm{N}$ oxides series, called nitroxyl or iminoxyl free radicals, is an important contribution to medicine. In medical studies they are used as spin-markers, spin-probes, spin traps and paramagnetic models of biologically active nuclear magnetic resonance imaging (MRI) [17] they are generally broad-spectrum compounds [18]. There are three basic conditions for the stability of the nitroxyl radicals, namely: a) delocalization of free valence; b) spatial shielding of the paramagnetic reaction center; (c) Resistance to disproportionation. The most commonly used nitroxyls today are derivatives of the following stable nitroxyl radicals (Figure 1):

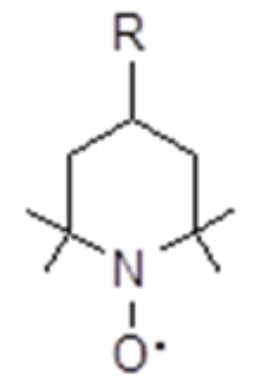

Figure 1. Nitroxyl radical structure
Where: $\mathbf{R}=\mathbf{H}$, TEMPO (2,2,6,6-tetramethyl4-oxo-piperidine-1-oxyl); $\mathbf{R}=\mathbf{O}, \mathbf{O}$-TEMPO (2,2,6,6-tetramethyl-4-amino-piperidine-1-

oxyl); $\mathbf{R}=\mathbf{N H}_{2}, \mathbf{A}$-TEMPO $(2,2,6,6-$ tetramethyl-4-oxo-piperidine-1-oxyl). It is believed that by its free valence, nitroxyls have an effect on the oxidative-reductive processes in the cell that are formed by the free radicals formation. The nitroxyl radicals having only one functional group are substances with relatively low acute toxicity. It has been shown that nitroxides at non-toxic concentrations are effective both in vitro and in vivo [19, 20].

There are several possible explanations for the nitroxyl radicals' protective effect: 1) due to SOD-mimetic action; 2) due to the reduction of metals having the potential to generate specific $\mathrm{OH}$ radicals; 3) termination of the free-radical chain reaction induced by alkyl, alkoxyl, alkylperoxyl radical species, and detoxifying drug-derived radicals, and 4) detoxification of toxic metals such as ferric and cupric ions. In vitro was detected the synergistic effect of the spin-labeled nitrosourea 1-ethyl-3- [4- $(2,2,6,6-$ tetramethylpiperidine-1-oxyl)] - 1-nitrosourea (SLENU) on the cytotoxicity of bleomycin and farmorubicin in human lymphoid leukemic tumor cells [21]. Recent studies have demonstrated the protective effect of SLENU against drug-induced oxidative stress in liver and blood in experimental animals [22, 23].

The aim of the current research is through experimental model of healthy mice to explore the possibility to reduce the oxidative stress (OS) induced by the L-dopa drug after its combining with: an essential oil isolated from Rosa damascena Mill., the vitamin $\mathrm{C}$ and synthetic antioxidant 1-ethyl-3- [4- (2,2,6,6tetramethylpiperidine-1-oxyl)] - 1-nitrosourea SLENU.

The antioxidants protective effects against the L-dopa oxidative toxicity were evaluated through the oxidative stress indicators - the lipid and protein oxidation end products measured as MDA, protein carbonyl content, and advanced glycation end products (AGEs) blood plasma of experimental mice.

\section{MATERIALS AND METHODS CHEMICALS}

Spin-labeled drug SLENU was previously synthesized by Gadzheva V et al 2001. Stannous Chloride dehydrated $\left(\mathrm{SnCl}_{2} .2 \mathrm{H}_{2} \mathrm{O}\right)$, the spin- trapping agent, PBS and $\mathrm{K}_{3}\left[\mathrm{Fe}\left(\mathrm{CN}_{6}\right)\right]$, 2-Thiobarbituric acid (TBA), L3,4 dihydroxyphenyl alanine (L-dopa), LAscorbic acid were purchased from SigmaAldrich Chemie GmbH (Germany). All other 
chemicals used in this study were analytical grade. Deionized and distillated water were used for all experiments. Essential Rose oil was provided from the Institute for Roses and Aromatic Plants, Kazanluk, Bulgaria.

\section{ANIMALS}

In the experiment were used male non-inbred albino mice (25-40 g). The experimental animals were housed in polycarbonate cages in controlled conditions: $12 \mathrm{~h}$ light/dark cycles, $18-23^{\circ} \mathrm{C}$ and humidity $55 \%$, with free access to tap water, provided by the Trakia University vivarium, Stara Zagora, Bulgaria. The animal procedures were in accordance with Directive 2010/63/EU on the protection of animals used for experimental and other scientific work, and approved by the Ethical Committee for Animals of BABH and Trakia University, Stara Zagora, Bulgaria (131/ 6000-0333/ 09.12.2015).

Mice were divided into five groups (12 animals in each group). The control group of mice was inoculated two i.p. injections with solvent, only. The second injection was administered $45 \mathrm{~min}$ after the first. To study the L-dopa effect we used the acute model of Bottiglieri et al., [24]. The mice from all tested groups (except controls) received either two i.p. injections of L-dopa $(100 \mathrm{mg} / \mathrm{kg})$ followed by benserazide $(10 \mathrm{mg} / \mathrm{kg})$. The second injection was administered $45 \mathrm{~min}$ after the first. The groups undergoing combination therapy were pre-treated first for one hour with i.p. injections in doses of $400 \mathrm{mg} / \mathrm{kg}$ of Ascorbic acid, Rose oil and after that received L-dopa and benserazide. The group with synthetic antioxidant SLENU was pretreated first for one hour with i.p. injections in doses of $40 \mathrm{mg} / \mathrm{kg}$ SLCNU [16] and after that received L-dopa and benserazide. All mice were sacrificed by light anesthesia (Nembutal $50 \mathrm{mg} / \mathrm{kg}$ i.p.) after $30 \mathrm{~min}$. Fresh blood (1-2 $\mathrm{cm}^{3}$ ) was collected directly from the heart in cold EDTA-containers $\left(5 \mathrm{~cm}^{3}\right.$ Monovette, Germany), and centrifuged at $4000 \mathrm{rpm}, 10$ min, $4^{\circ} \mathrm{C}$ and plasma samples were carefully separated.

\section{EX vivo SPECTROPHOTOMETRY ASSAY FOR EVALUATION THE LEVELS OF MDA}

To evaluate the levels of lipid peroxidation, Thiobarbituric acid reactive substances (TBARS) assay was used, which measures MDA reactive substances [25]. The spectrophotometric measurements were performed on a Thermo Scientific spectrophotometer.
ENZYME-LINKED IMMUNOSORBENT ASSAY

Preliminarily were determined the total protein amount in the test sample with the Total Protein Kit, Human. Each protein sample were diluted to $10 \mu \mathrm{g} / \mathrm{mL}$ in $1 \mathrm{X}$ PBS, $\mathrm{pH}=7.4$ prior to use in the assay. Protein carbonyl content was measured using an OxiSelect protein carbonyl ELISA kit (Cell Biolabs). Briefly, the BSA standard (reduced/oxidized) and the assayed samples $(10 \mu \mathrm{g} / \mathrm{mL})$ were adsorbed on a 96-well plate for 2 hours at $37^{\circ} \mathrm{C}$. Protein carbonyl found in samples and standard reacted with DNPH to form DNP hydrazone, treated with anti-DNP antibody and HRP conjugated secondary antibody. Protein carbon content in the samples was determined by a standard curve prepared from the absorbance obtained on the basis of the oxidized/reduced BSA standards and the protein carbonyl content in the samples were calculated in $\mathrm{nmol} / \mathrm{mg}$.

The AGEs level was similarly assessed with an OxiSelect AGE competitive ELISA kit (Cell Biolabs). an AGE conjugate is coated on an ELISA plate. The unknown AGE protein samples or AGEBSA standards are then added to the AGE conjugate preabsorbed ELISA plate. After a brief incubation, an anti-AGE polyclonal antibody is added, followed by an HRP conjugated secondary antibody. The content of AGE protein adducts in unknown samples is determined by comparison with a predetermined AGE-BSA standard curve.

\section{STATISTICAL ANALYSIS}

Statistical analysis was performed with Statistica 7, StaSoft, Inc. and the results were expressed as means \pm S.E. All data were expressed as mean $\pm \mathrm{SE}$ and obtained by oneway ANOVA. p>0.05 was considered statistically significant. To define which groups are different from each other were used LSD post hoc test.

\section{RESULTS}

In the current manuscript was investigated the possibilities of reducing the oxidative stress induced by L-dopa by combining with liposoluble Rose oil and spin-labeled nitrosourea SLENU that cross the blood-brain barrier. The results were compared with animals treated with L-dopa alone and with a reference antioxidant -vitamin C (ascorbic acid). Spin-labeled nitrosourea SLENU was administered at a dose exhibiting in vivo maximum antioxidant activity (maximum "curative" dose) 40mg/kg [21]. Based on literature data [26], we selected the $400 \mathrm{mg} / \mathrm{kg}$ dose as "protector" for essential oils and the referent antioxidants -ascorbic acid. 
MDA LEVELS IN BLOOD PLASMA

Figure 2 shows the plasma MDA level in healthy untreated mice and mice treated with
NIKOLOVA G.

L-dopa and combinations of L-dopa with synthetic and natural antioxidants.

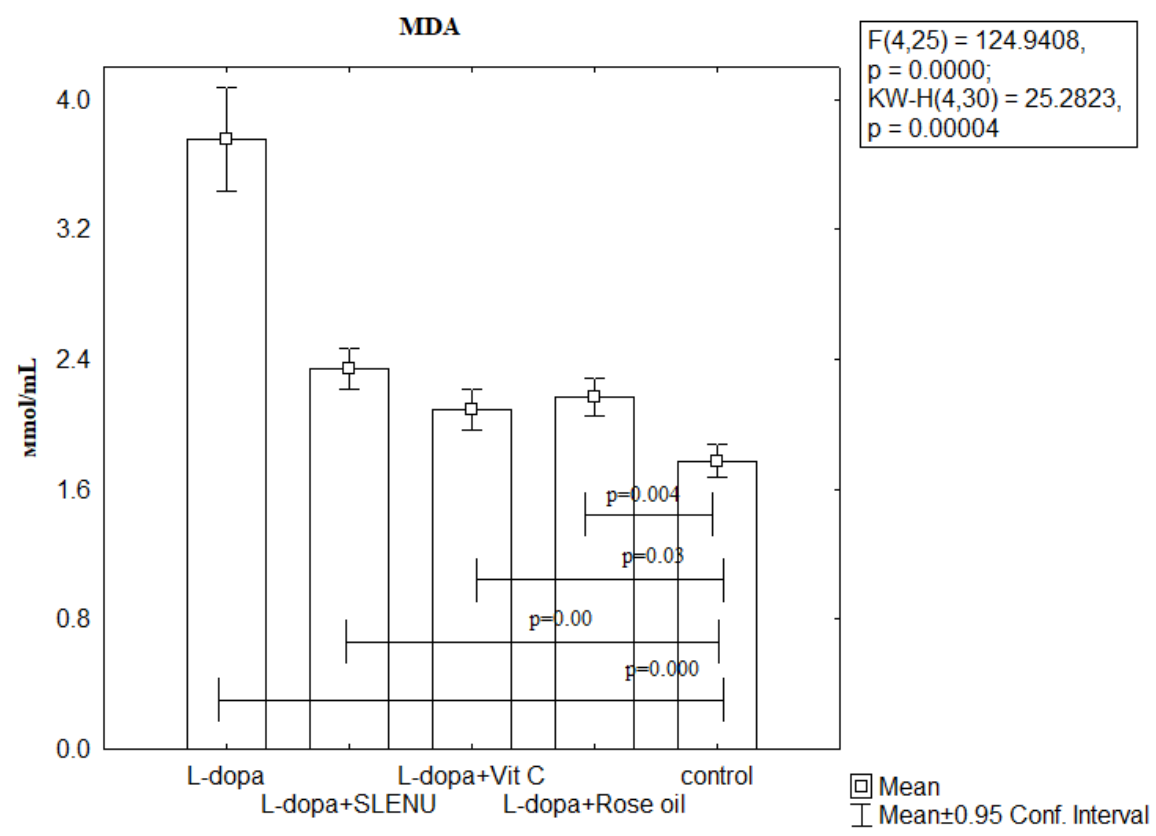

Figure 2. The lipid peroxidation products measured as MDA level in mice treated with L-dopa alone and in combination of L-dopa + SLENU/ Ascorbic acid/ Rose oil were statistically significant higher than controls, $\mathrm{p}<0.00$, t-test; $(\mathrm{F}(4,25)=2316.3257, \mathrm{p}=0.0000 ; \mathrm{KW}-\mathrm{H}(4,30)=27.8834, \mathrm{p}=0.00001)$. According the LSD post hoc test L-dopa vs controls $\mathrm{p}=0.000130$; L-dopa + SLENU vs controls $\mathrm{p}=0.000173$; L-dopa + Ascorbic acid vs controls $\mathrm{p}=0.028226$; L-dopa + Rose oil vs controls $\mathrm{p}=0.004231)$. The results are presented as mean \pm S.E. $\mathrm{p}<0.01 ;(*)$ relative to controls; $(* *)$ relative to L-dopa.

The lipid peroxidation products measured as MDA level from mice treated with L-dopa alone was statistically higher compared to controls (mean $3.75 \pm 0.12 \mu \mathrm{mol} / \mathrm{mL}$, vs mean $1.77 \pm 0.03 \mu \mathrm{mol} / \mathrm{mL}, \mathrm{p}<0.00, \mathrm{t}-$ test $)$. The Ldopa +SLENU combination the plasma MDA is also statistically higher than controls (mean $2.34 \pm 0.04 \mu \mathrm{mol} / \mathrm{mL}$, vs mean $1.77 \pm$ $0.03 \mu \mathrm{mol} / \mathrm{mL}, \mathrm{p}<0.00, \mathrm{t}$-test) and statistically lower than samples treated with L-dopa alone (mean $2.34 \pm 0.04 \mu \mathrm{mol} / \mathrm{mL}$, vs mean $3.75 \pm$ $0.12 \mu \mathrm{mol} / \mathrm{mL}, \mathrm{p}<0.00, \mathrm{t}$-test). The MDA level in the combination L-dopa+ Asc. acid is statistically significantly higher than the controls (mean $2.08 \pm 0.04 \mu \mathrm{mol} / \mathrm{mL}$ vs mean $1.77 \pm 0.03 \mu \mathrm{mol} / \mathrm{mL}, \mathrm{p}<0.00, \mathrm{t}$-test) and statistically significantly lower than those of mice treated with L-dopa alone (mean $2.08 \pm$ $0.04 \mu \mathrm{mol} / \mathrm{mL}$ vs mean $3.75 \pm 0.12 \mu \mathrm{mol} / \mathrm{mL}$, p $<0.00, \mathrm{t}$-test). The MDA level in combination L-dopa+Rose oil is statistically significantly higher than controls (mean 2.16 $\pm 0.05 \mu \mathrm{mol} / \mathrm{mL}$ vs mean $1.77 \pm 0.03 \mu \mathrm{mol} / \mathrm{mL}$, $\mathrm{p}<0.00$, t-test), and statistically lower than samples treated with L-dopa alone (mean 2.16 $\pm 0.05 \mu \mathrm{mol} / \mathrm{mL}$ vs mean $23.75 \pm$ $0.12 \mu \mathrm{mol} / \mathrm{mL}, \mathrm{p}<0.00$, t-test).

\section{PROTEIN CARBONYL CONTENT (PCC)} DETERMINATION IN BLOOD PLASMA

Figure 3 shows the protein carbonyl content in blood plasma from mice treated with L-dopa alone and in combination with antioxidants. Compared to controls the PCC in L-dopa group is statistically significant higher then controls (mean $5.23 \pm 0.01 \mathrm{nmol} / \mathrm{mg}$, vs mean $1.55 \pm 0.04 \mathrm{nmol} / \mathrm{mg}, \mathrm{p}<0.000, \mathrm{t}$-test), and all group pretreated with combination L-dopa + antioxidants.

The PCC measured in group treated with Ldopa + SLENU is statistically significantly higher compared to controls (mean $4.51 \pm 0.03$ $\mathrm{nmol} / \mathrm{mg}$ vs. mean $1.55 \pm 0.04 \mathrm{nmol} / \mathrm{mg}, \mathrm{p}$ $<0.000$, t-test). Against the group treated with L-dopa alone the PCC is statistically lower (mean $4.51 \pm 0.03 \mathrm{nmol} / \mathrm{mg}$ vs. mean $5.23 \pm$ $0.01 \mathrm{nmol} / \mathrm{mg}, \mathrm{p}<0.000$, t-test). Statistically significant increase in PCC is observed in group treated with L-dopa +Asc acid versus controls (mean $3.18 \pm 0.09 \mathrm{nmol} / \mathrm{mg}$ vs. mean $1.55 \pm 0.04 \mathrm{nmol} / \mathrm{mg}, \mathrm{p}<0.000$, t-test), but compared with group treated with L-dopa alone, the PCC level was statistically significant lower (mean $3.18 \pm 0.09 \mathrm{nmol} / \mathrm{mg}$ 
vs. $5.23 \pm 0.01 \mathrm{nmol} / \mathrm{mg}, \mathrm{p}<0.00$, t-test). The L-dopa + Rose oil combination versus controls was statistically significantly higher (mean $3.07 \pm 0.02 \mathrm{nmol} / \mathrm{mg}$ vs. mean $1.55 \pm$ $0.04 \mathrm{nmol} / \mathrm{mg}, \quad \mathrm{p} \quad<0.000, \quad \mathrm{t}$-test), and
NIKOLOVA G. statistically significantly lower in samples treated with L-dopa alone (mean $3.07 \pm 0.02$ $\mathrm{nmol} / \mathrm{mg}$ vs. mean $5.23 \pm 0.35 \mathrm{nmol} / \mathrm{mg}, \mathrm{p}$ $<0.000$, t-test).

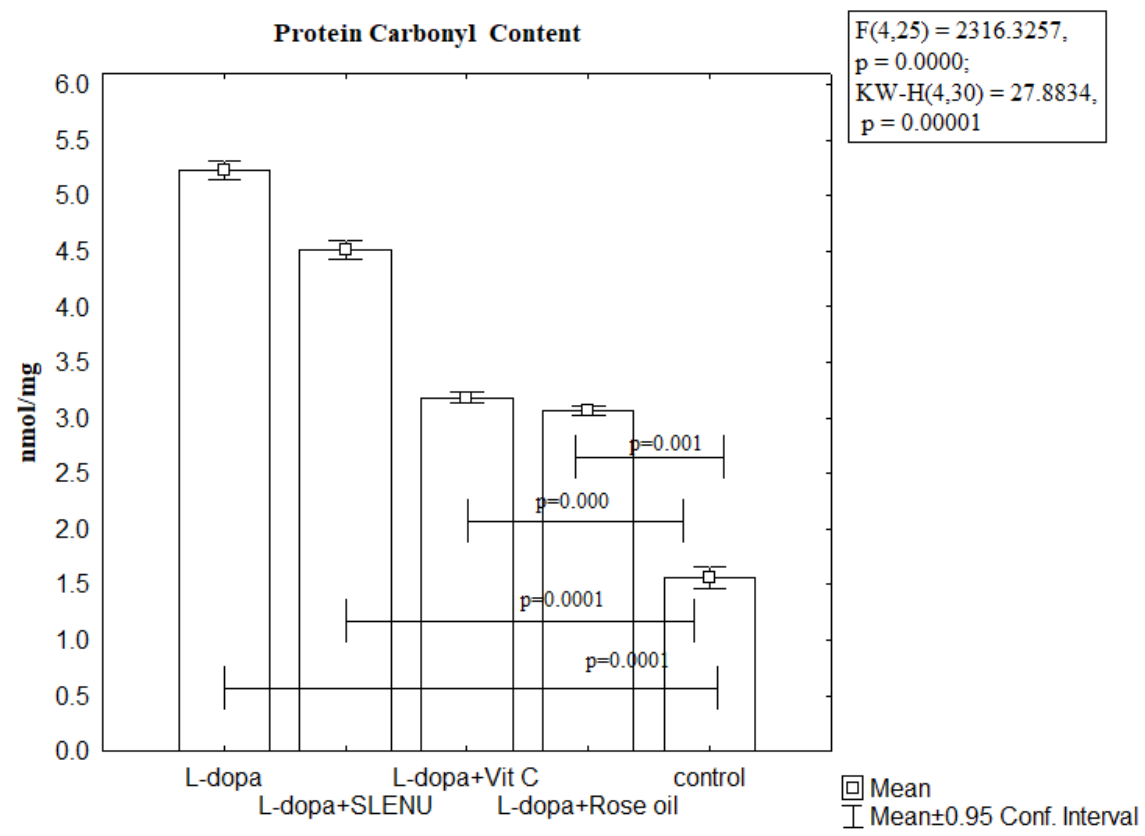

Figure 3. The protein carbonyl content (PCC) in mice treated with L-dopa alone and in combination of L-dopa + SLENU/ Ascorbic acid/ Rose oil were statistically significant higher than controls, $\mathrm{p}<0.00$, t-test; $(\mathrm{F}(4,25)=$ $124.9408, \mathrm{p}=0.0000 ; \mathrm{KW}-\mathrm{H}(4,30)=25.2823, \mathrm{p}=0.00004)$. According the LSD post hoc test L-dopa vs controls $\mathrm{p}=0.0001$; $\mathrm{L}$-dopa + SLENU vs controls $\mathrm{p}=0.0001$; $\mathrm{L}$-dopa + Ascorbic acid vs controls $\mathrm{p}=0.000$; Ldopa + Rose oil vs controls $p=0.001)$. The results are presented as mean \pm S.E. $p<0.05$; (*) relative to controls; $(* *)$ relative to L-dopa.

\section{ADVANCED GLYCATION END PRODUCTS (AGES) BLOOD PLASMA}

The AGEs (Figure 4) in blood plasma in group treated with L-dopa alone was statistically significantly higher compared to control group $(981.36 \pm 5.99 \mu \mathrm{g} / \mathrm{ml}$ vs $431.45 \pm 7.77 \mu \mathrm{g} / \mathrm{ml}$, $\mathrm{p}<0.000$, t-test). Statistically significantly increase was observed in pretreated with antioxidant groups compared to controls: Ldopa + SLENU versus controls $706.91 \pm 10.1$ $\mu \mathrm{g} / \mathrm{ml}$ vs $431.45 \pm 7.77 \mu \mathrm{g} / \mathrm{ml}, \mathrm{p}<0.000$, t-test; L-dopa + Ascorbic acid versus controls 685.3 $\pm 8.8 \mu \mathrm{g} / \mathrm{ml}$ vs $981.36 \pm 5.99 \mu \mathrm{g} / \mathrm{ml}, \mathrm{p}<0.000$, t-test; and versus L-dopa alone L-dopa + SLENU versus L-dopa $706.91 \pm 10.1 \mu \mathrm{g} / \mathrm{ml}$ vs $981.36 \pm 5.99 \mu \mathrm{g} / \mathrm{ml}, \mathrm{p}<0.000$, t-test; L-dopa + Ascorbic acid versus controls $685.3 \pm 8.8$ $\mu \mathrm{g} / \mathrm{ml}$ vs $981.36 \pm 5.99 \mu \mathrm{g} / \mathrm{ml}, \mathrm{p}<0.000$, t-test.

\section{CORRELATIONS BETWEEN PARAMETERS}

All parameters show positive correlation MDA vs AGEs show $r=0.886, p=0.000$; MDA vs $\mathrm{PCC} \mathrm{r}=0.823, \mathrm{p}=0.000$; $\mathrm{PCC}$ vs AGEs show $\mathrm{r}=0.899, \mathrm{p}=0.000$.

\section{DISCUSSION}

Protein carbonyl formation is an important marker for protein oxidation that results from free radical attack on amino acid side chains [27]. The PCC increases in stress and the accumulating carbonyls cause protein damage and dysfunction. Another oxidative stressrelated biomarker was AGEs. Due to their synergism with oxidative stress, AGEs have been associated with all major neurodegenerative diseases. Augmented accumulation of AGEs may indicate an accelerated process of aging-related deterioration that likely accompanies neurodegeneration. However, it should be noted that AGEs mainly accumulate on longlived proteins. The analysis of AGEs in blood may therefore not necessarily reflect their tissue levels, yet circulating AGEs keep their biomarker potential [27]. 


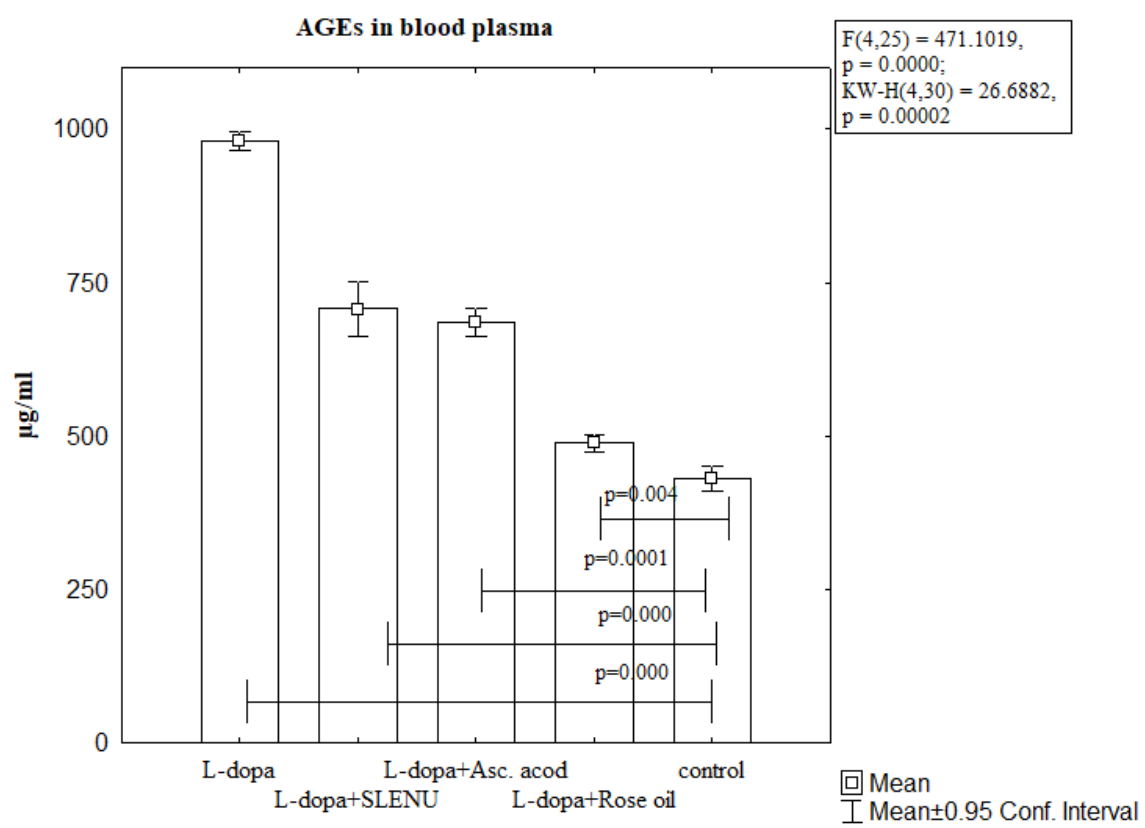

Figure 4. The Advanced glycation end products (AGEs) blood plasma in mice treated with L-dopa alone and in combination of L-dopa + SLENU/Ascorbic acid/Rose oil were statistically significant higher than controls, $\mathrm{p}<0.00$, t-test; $(\mathrm{F}(4,25)=471.1019, \mathrm{p}=0.0000 ; \mathrm{KW}-\mathrm{H}(4,30)=26.6882, \mathrm{p}=0.00002)$. According the LSD post hoc test L-dopa vs controls $\mathrm{p}=0.000$; L-dopa + SLENU vs controls $\mathrm{p}=0.000$; L-dopa + Ascorbic acid vs controls $\mathrm{p}=0.0001 ; \mathrm{L}-\mathrm{dopa}+$ Rose oil vs controls $\mathrm{p}=0.004)$. The results are presented as mean \pm S.E. $\mathrm{p}<0.05 ;(*)$ relative to controls; $(* *)$ relative to $\mathrm{L}-$ dopa.

The obtained from our study results in mice blood after treatment with L-dopa compared to controls showed a significant increase in lipid oxidation end products (MDA, p <0.00) of proteins (PCC, p <0.00) and advanced glycation end products (AGEs, $\mathrm{p}<0.00$ ). These results can be related to the presence of oxidative stress after treatment with L-dopa. The effect of spin-labeled SLENU nitrosourea on induced oxidative stress under L-dopa in experimental models of healthy mice showed that after L-dopa + SLENU administration, the MDA levels $\mathrm{p}<0.00$, PCC $\mathrm{p}<0.00$ and AGEs $\mathrm{p}<0.00$ are declining. A similar statistically significant decrease in the levels of oxidative stress is also observed in the combination of essential oil + L-dopa and referent vitamin C + $\mathrm{L}$-dopa. The results obtained from treatment with L-dopa and combination of L-dopa and synthetic or natural antioxidants can summarize as in vivo successfully neutralizing the ongoing oxidative processes in blood resulting in oxidative status normalization in the test animals. Natural polyphenols and terpenes contained in rose oils may have a protective effect on a number of pathological conditions, including neurodegenerative diseases [28]. Phenols and flavonoids are the main ingredients noted in most of the ethereal plants (as well as rose oil) reported by many researchers to have antioxidant and free radical activity $[6,29,30]$. The neuroprotective effects of many polyphenols and terpenes have the ability to pass through the blood-brain barrier and directly capture the pathological concentrations of ROS and RNS and chelated transient metal ions and exert antioxidant activity directly in brain cells [28].

Essential oils as antioxidants have been studied in detail to investigate their protective role for highly unsaturated lipids in animal tissues [31]. They shown their actions as hepatoprotective agents [32] and coincide with our results. Furthermore, oils possess antioxidant properties at extremely low dilution rates administered either by inhalation or by lipophilic fractions, interacting with the lipid parts of the cell membranes, thereby altering the calcium ion channels activity and in some dosas saturated the membranes [33]. The results obtained from a blood MDA after treatment with the combinations L-dopa + ascorbic acid showed levels commensurate with the controls and statistically decreased from the L-dopa-only group. This appears to confirm that the endogenous antioxidant ascorbic acid can successfully limit peroxidation processes in lipids under the described experimental conditions. Combinations with ascorbic acid showed a statistically significant decrease in PCC compared to L-dopa treated only mice and a statistically significant increase compared to control mice $(p=0.00)$. Studies have shown that vitamin $\mathrm{C}$ can slowly migrate proteins 
under oxidative conditions and protect them from UV oxidation [15]. In plasma, vitamin C is not able to protect proteins from the action of ROS and oxidation-generating systems but is able to protect isolated lipoproteins from oxidation [15].

\section{CONCLUSION}

Antioxidants - polyamines, flavonoids, ascorbic acid, plant phenols, vitamin $\mathrm{C}$, vitamin $\mathrm{E}$, etc. can stabilize the membranes by reducing their permeability and are able to bind to the free fatty acids. It is believed that essential oils can act as antioxidant agents. The use combinations of L-dopa with natural or synthetic antioxidants, may be a necessary approach in modern therapy of Parkinson's disease. The combination of L-dopa+Rose oil improves oxidative status in experimental animals and could be applied in medical practice.

\section{REFERENCES}

1. Silva, B., Breydo, L., Fink, A., and Uversky, V. Agrochemicals, $\alpha$-synuclein, and Parkinson's disease. Molecular neurobiol, 47(2): 598-612, 2013.

2. Petzinger, G., Holschneider, D., Fisher, B., McEwen, S., Kintz, N., Halliday, M., Toy, W., Walsh, J., Beeler, J. and Jakowec, M. The effects of exercise on dopamine neurotransmission in Parkinson's disease: targeting neuroplasticity to modulate basal ganglia circuitry. Brain plasticity, 1(1): 2939, 2015.

3. Davies, S., Kennewell, P., Russell, A., Seden, P., Westwood, R. and Wynne, G., Stemistry: the control of stem cells in situ using chemistry. $J$ of med. chem. 58(7): 2863-2894, 2015.

4. Fahn, S. The medical treatment of Parkinson disease from James Parkinson to George Disorders, 30(1): 4-18, 2015.

5. Fox, S.H., Katzenschlager, R., Lim, S.Y., Barton, B., de Bie, R.M., Seppi, K., Coelho, M., Sampaio, C. and Movement Disorder Society Evidence- Based Medicine Committee, International Parkinson and movement disorder society evidence- based medicine review: Update on treatments for the motor symptoms of Parkinson's disease. Movement Disorders, 2018.

6. Nikolova, G., Karamalakova, Y., Kovacheva, N., Stanev, S., Zheleva, A. and Gadjeva, V. Protective effect of two essential oils isolated from Rosa damascena Mill. and Lavandula angustifolia Mill, and two classic antioxidants against L-dopa oxidative toxicity induced in healthy mice. Regulat.

NIKOLOVA G.

Pharmacol. 81:1-7, 2016

7. Duke, J.A., Cseke, L.J., Warber, S., Kirakosyan, A., Brielmann, H.L. and Kaufman, P.B., 2016. Natural products from plants. CRC press.

8. Slavov, A., Vasileva, I., Stefanov, L. and Stoyanova, A., 2017. Valorization of wastes from the rose oil industry. Reviews in Environment Sci and Bio/Technol. 16(2): 309-325.

9. Mahmood, N., Piacente, S., Pizza, C., Burke, A., Khan, A.I. and Hay, A. The Anti-HIV Activity and Mechanisms of Action of Pure Compounds Isolated fromRosa damascena. Biochem and biophys research communicat. 229(1):73-79, 1996.

10.Hongratanaworakit, T. Relaxing effect of rose oil on humans. Nat Prod Commun, 4(2): 291-6, 2009

11.Valnet, C. Essential Oils and Aromatherapy. Edizioni REI, 2015

12.Lei, W., Modulation of inflammatory responses by Sutherlandia frutescens. University of Missouri-Columbia. 2015.

13.Smirnoff, N., Ascorbic acid metabolism and functions: a comparison of plants and mammals. Free Radical Biology and Medicine, 2018.

14.Rahal, A., Kumar, A., Singh, V., Yadav, B., Tiwari, R., Chakraborty, S. and Dhama, K., Oxidative stress, prooxidants, and antioxidants: the interplay. BioMed research international, 2014.

15. Halliwell, B. and Gutteridge, J. Free radicals in biology and medicine. Oxford University Press, USA. 2015.

16.Gadjeva, V., Tolekova, A. and Vasileva, M. Effect of the spin-labelled 1-ethyl-1nitrosourea on CCNU-induced oxidative liver injury. Die Pharmazie-An Intern. J of Pharmaceut. Sci. 62(8): 608-613, 2007.

17.Gadjeva, V., Zheleva, A., Raikova, E. Modulating Effect of New Potential Antimelanomic Agents, Spin labeled Triazenes and Nitrosoureas on Dopaoxidative Activity of Tyrosinase. Cancer Bioch. Bioph. 17(2):90-108, 1999.

18.Roger A. Sheldon, Isabel W. C. E. Arends, Review paper: Organocatalytic Oxidations Mediated by Nitroxyl Radicals, Advanc synth and catal. Special Issue: Org Catal. 346(9- 10): 1051-1071, 2004

19.Gadzheva, V., Ichimori, K., Raikov, Z. and Nakazawa, H. New method to measure the carbamoylating activity of nitrosoureas by electron paramagnetic resonance spectroscopy. Free rad. res. 27(2):197-206, 1997. 
20. Karamalakova, Y., Sharma, J., Sharma, R.K., Gadjeva, V., Kumar, R. and Zheleva, A. Comparative investigation on radical scavenging activity and protective properties of natural isolated and synthetic antioxidants. Biotechnol \& Biotechnolog Equipm, 26(sup1): 175-179, 2012.

21.Gadzheva, V., Koldamova, R. Spin-labeled 1-alkyl-1-nitrosourea synergists of antitumor antibiotics. Anti-cancer Drug Design. 16 (4-5): 247-253, 2001.

22.Gadjeva, V., Grigorov, B., Nikolova, G., Tolekova, A., Zheleva, A. and Vasileva, M. Protective effect of spin-labeled 1-ethyl-1nitrosourea against oxidative stress in liver induced by antitumor drugs and radiation. BioMed research international, 2013.

23.Karamalakova, Y., Chuttani, K., Sharma, R., Zheleva, A., Gadjeva, V., Mishra, A. Biological evaluation of new potential anticancer agent for tumour imaging and radiotherapy by two methods: $99 \mathrm{mTc}-$ radiolabelling and EPR spectroscopy. Biotechnol \& Biotechnolog Equipm. 28(6):1172-1180, 2014.

24.Bottiglieri, T., Arning, E., Wasek, B., Nunbhakdi-Craig, V., Sontag, J. M., Sontag, E. Acute administration of LDOPA induces changes in methylation metabolites, reduced protein phosphatase 2A methylation, and hyperphosphorylation of Tau protein in mouse brain. The $J$ of Neurosci. 32(27): 9173-9181, 2012.

25.Plaser, Z.A., Cushman, L.L., Jonson, B.C. Estimation of product of lipid peroxidation (Malonyl Dialdehyde) in biochemical systems. Anal. Biochem. 16: 359-364, 1966.

26.Umezu, T., Nagano, K., Ito, H., Kosakai, K., Sakaniwa, M., Morita, M. Anticonflict effects of lavender oil and identification of
NIKOLOVA G. its active constituents. Pharmacol Biochem and Behav. 85(4): 713-721, 2006.

27.Hondur, G., Göktaş, E., Yang, X., AlAswad, L., Auran, J.D., Blumberg, D.M., Cioffi, G.A., Liebmann, J.M., Suh, L.H., Trief, D. and Tezel, G. Oxidative StressRelated Molecular Biomarker Candidates for Glaucoma. Investig ophthalmol and visual sci, 58(10):4078-4088, 2017.

28.Bergeron, R.J., Wiegand, J., McManis, J.S. and Bharti, N. Desferrithiocin: a search for clinically effective iron chelators. $J$ of medchem, 57(22):9259-9291, 2014.

29.Manjamalai, A., and Grace, V. B. Antioxidant activity of essential oils from Wedelia chinensis (Osbeck) in vitro and in vivo lung cancer bearing C57BL/6 mice. Asian Pacific $J$ of Cancer Prevent. 13: 3065-3071, 2012.

30.Barkat, M., and Imène L. Antioxidant activity of the essential oil from the flowers of Lavandula stoechas. $\mathrm{J}$ of Pharmacognand Phytother. 4(7): 96-101, 2012

31.Li, T.S., Liu, W.C., Zhao, P.Y. and Kim, I.H., Evaluation of essential oil or/and emulsifier in low energy density diets on growth performance, nutrient digestibility, blood cholesterol and meat quality in finishing pigs. Ital. J. of An. Sci., 16(4): 624-630, 2017.

32.Sharifi-Rad, J., Sureda, A., Tenore, G.C., Daglia, M., Sharifi-Rad, M., Valussi, M., Tundis, R., Sharifi-Rad, M., Loizzo, M.R., Ademiluyi, A.O. and Sharifi-Rad, R. Biological activities of essential oils: From plant chemoecology to traditional healing systems. Molecules, 22(1):70, 2017

33.Stine, K.E. and Brown, T.M. Principles of toxicology. Crc Press. 2015. 